\title{
JOGOS LINGUAGEIROS NA INFÂNCIA E O ENLACE POÉTICO
}

\section{LANGUAGE GAMES IN CHILDHOOD AND THE POETIC $L I N K$}

\author{
Elisangela Maria da SILVA ${ }^{1}$ \\ Glória Maria Monteiro de CARVALHO²
}

Resumo: Objetivamos discutir o poder que os textos da tradição oral e os literários exercem no imaginário infantil. Para tanto, tivemos por base o quadro teórico de Lemos e colaboradores e a Psicanálise de base Freud lacaniana. Metodologicamente realizamos uma discussão teórica sobre uma aproximação entre Aquisição de linguagem, Literatura - poesia - e Psicanálise, a partir da hipótese de que a criança é atraída pelos jogos linguageiros da função materna ou de quem exerce essa função, revelando a possibilidade de a criança se sustentar na relação com o outro e, assim, produzir significações novas como os poetas.

Palavras-chave: Jogos linguageiros. Som da voz materna. Linguagem infantil.
Abstract: We aim to discuss the power that the texts of the oral tradition and the literary have in the children's imagination. For this, we were based on the theoretical framework of Lemos and collaborators and the Freud lacanian psychoanalysis. Methodologically, we conduct a theoretical discussion about an approximation between Language Acquisition, Literature poetry - and Psychoanalysis, based on the hypothesis that the child is attracted to the language games of the maternal function or who performs this function, revealing the possibility of the child to support himself in relation to the other and thus produce new meanings like poets.

Keywords: Aesthetic emotion. Language games. Fantasy. Language.

1Silva.UNICAP. E-mail: elisangelasilva1718@gmail.com. ORCID ID: https://orcid.org/0000-0001-8404-5190. 2 Carvalho. UNICAP. E-mail: gmmcarvalho@uol.com.br. ORCID ID: http://orcid.org/0000-0003-0595-1764. 
- | Jogos linguageiros na infância e o enlace poético

"Carrego meus primórdios no andor.

Minha voz tem um vício de fontes.

Eu queria avançar para o começo.

Chegar ao criançamento das palavras.

Lá onde elas ainda urinam na perna. Antes mesmo que sejam modeladas pelas mãos. Quando a criança garatuja o verbo para falar o que não tem.

Pegar no estame do som. Ser a voz de um lagarto escurecido. Abrir um descortínio para o arcano." (BARROS, 1996, p. 47)

\section{Introdução}

Este artigo propõe uma discussão a respeito do poder que os textos da tradição oral e os literários exercem no imaginário infantil, fazendo aproximação entre Aquisição de linguagem, Literatura - poesia - e Psicanálise. Inspiramo-nos no princípio tão caro à psicanálise e a vários autores no campo da literatura, a ideia de falta, muito bem traduzida por Manuel de Barros no Livro Sobre Nada (1996, p. 67), quando diz que: "tem mais presença em mim o que me falta". Guiamo-nos na ideia de Freud (1908), segundo a qual a linguagem preserva a relação entre o brincar infantil e a criação poética, podendo oferecer à criança um universo linguístico pautado pela invenção, pela fantasia e pela emoção, como o fazem os escritores. Como se através dos seus escritos procurassem reencontrar a satisfação original perdida, numa espécie de embate com o indizível, numa luta de palavras em torno do que Morais (2006, p. 48) chama de "eterna meia-noite, hora dos fantasmas e lobisomens, em que o estilo, a singularidade irredutível se faz no encontrolimite com o impossível de dizer".

Neste jogo entre o brincar e a criação poética encontra-se a ideia de falta, visto que, segundo Freud (1908), nunca renunciamos a nada, apenas trocamos uma coisa por outra. A criança aprendeu a deixar a mãe em função de outras coisas, como uma cantiga, uma história. E o escritor, pela obra literária, continua ou substitui o brincar infantil. Dessa forma, seguimos a premissa de que, ao ter contato com os textos da tradição oral e os literários, é ofertado à criança buscar vestígios e dar contorno para o objeto perdido, considerando ser possível, pela poesia, privilegiar a acústica das palavras, da lalação contida na sonoridade, suscitar inúmeras significações, num esvaziamento de sentido, fazendo surgir algo novo como nos versos da epígrafe. 


\section{Emoção estética, efeitos de sentido e estruturação do psiquismo}

A vocação para a poesia tem origem na mais remota infância de muitos escritores. Em Graciliano Ramos, a infância surge como experiência em seu livro de memória intitulado Infância (1992); nele o autor não resume esse período de forma cronológica, mas o converte numa experiência primordial. Ele retorna aos primeiros anos da vida para mostrar que os textos orais da infância se encontram na retaguarda de toda armação de linguagem que o adulto recria posteriormente.

Assim como Graciliano Ramos (1992, 1996), o poeta Jorge de Lima (1978) mostra que a poesia esteve na sua base, ou seja, no berço, embalando-o com cantigas e histórias, motivando-o a escrever um poema quando tinha apenas sete anos. Com o poeta Manoel Bandeira não foi diferente; em Itinerário de Pasárgada (1996) o autor se remete aos primórdios da infância para falar de seu manancial de sentimentos que ele identifica como "natureza artística". Segundo o autor, seu primeiro contato com a poesia deu-se pela escuta de contos de fada e história da carochinha.

Em Escritos Criativos e Devaneios (1908), Freud delineia uma aproximação entre a poesia e o brincar infantil, interrogando-se se a forma como a criança constrói seu mundo de linguagem e de brinquedo não admitiria nela um escritor criativo. Tal aproximação nos remete a Sobral e Viana (2014, p. 436) quando afirmam que:

\section{[...] ao brincar, a criança articula elementos fundamentais à estruturação psíquica. O movimento pulsional do seu corpo passa a se estruturar em um ato de fala e as palavras, como significantes, são usadas em sua potência criativa. Nomeando, a criança pode situar seu desejo em uma fala, no laço com o outro.}

Sobre esse aspecto Lacan (1985, p. 195) afirma que "enquanto suporte formal, o significante ${ }^{3}$ atinge um outro que não aquele que ele é cruamente, ele, como significante, um outro que ele afeta e que dele é feito sujeito". Nesse afetamento, "a língua na infância, em seu enredamento discursivo com os textos da cultura, permite à criança exercer suas experiências estéticas e literárias" (BELINTANE, 2013, p. 18).

Belintane (2013, p. 18) também delineia uma aproximação entre a fala da criança e as produções poéticas, destacando uma passagem de Graciliano Ramos no texto Infância (1992), em que o autor, para se proteger de uma ameaça vinda do mundo adulto, em que "o sapo boi morde como cachorro e, se pega um cristão, só o larga quando o sino toca" entra em uma associação que vai evocar um outro sapo, o da cantiga de ninar:

3 Trata-se da Lei da castração - metáfora paterna (LACAN, 1998, p. 279). 
- | Jogos linguageiros na infância e o enlace poético

\author{
Sapo cururu \\ Da beira do rio. \\ Não me bote na água, \\ Maminha, \\ Cururu tem frio. \\ Cantiga para embalar criança. Os cururus do açude choravam com frio, \\ De muitos modos, gritando, soluçando, exigentes ou resignados. Eu também \\ Tinha frio e gostava de ouvir os sapos. (BELINTANE, 2013, p. 18).
}

Outro exemplo apresentado pelo autor se refere ao encaixe métrico realizado por uma criança de cinco anos:

Gustavo disse a sua tia: "fiz uma música para você e para o Claudemir.

Quer ver?" E começou a cantar:

"Alecrim, alecrim dourado

Que nasce no campo

Sem ser semeado..."

Repetiu mais uma vez sem mudar uma palavra sequer. De repente, no verso seguinte, engata, no ritmo e na métrica, a seguinte palavra:

"Foi o Clau de miiiir

Que me disse assim

Que a flor do campo

É o alecrim. (BELINTANE, 2013, p. 19)

A partir do exemplo acima, o autor chama atenção para "a associação que a criança faz entre a música que a tia cantava para ele cotidianamente e o nome de seu tio", afirmando que o encaixe métrico realizado pela criança é surpreendente, visto que:

O verso "foi o Claudemir", cantando no ritmo e na melodia da música, corresponde ao segmento métrico original "foi meu amor!", e ainda reformula o sentido geral da cantiga, assimilando a ela sua proposta inicial de fazer uma homenagem à tia, introduzindo o nome do tio na pauta. (BELINTANE, 2013, p. 19).

O autor apresenta outro caso, o de Rafaela de 1,9 ano, no seguinte diálogo com a mãe: 
Mãe: - Como se chama o seu ursinho?

Rafaela: - Se chama solidom (solidão).

Na fala de Rafaela, segundo Belintane (2013, p. 19), "temos um efeito associativo com a cantiga Se essa rua fosse minha, mais precisamente com o verso "Nesta rua, nesta rua tem um bosque que /que se chama, que se chama solidão".

Tais exemplos tornam visíveis a presença de uma dimensão inconsciente e de um movimento próprio da língua, com seus efeitos metafóricos e metonímicos. Esses processos, segundo Lemos (2002, p. 52), são definidos: "o primeiro pela substituição, em uma estrutura, de um termo por outro, e o segundo pela combinação ou contiguidade na relação de um termo a outro".

Assim, podemos pensar que a criança desde o nascimento está submetida aos jogos linguageiros da função materna, visto que cada grito, cada choro, cada gesto da criança será interpretado pelos pais e recoberto por falas, cantos e outras possibilidades da língua; por outro lado, os acalantos, contos e ludismos linguísticos vão se enredando e constituindo um outro modo de se posicionar na linguagem. Esse movimento de atribuição de sentido e de expansão parte desse outro, visto que os equívocos e os nonsenses se fazem presentes e são fundamentais nessa divisão subjetiva. Como a nomeação de uma demanda da criança, do tipo "mamãe te quero", mas sendo nomeada como "a mamadeira já vai" ou os resmungos emitidos espontaneamente pela criança que vão sendo interpretados pela mãe na tentativa de atribuir a estes o estatuto de palavra.

Nessa divisão subjetiva, a polaridade do sentido vai se formando, e juntamente com ela ficam ali os traços do sem sentido (nonsense) que se presentificaram no próprio ato fundador da palavra. Nonsenses que, segundo Belintane (2013, p. 34), "tendem a permanecer ligados à subversão (ao puro prazer de emitir sons), que fisgam sentidos inusitados ou mesmo que se perdem no real da língua". Fazendo-nos lembrar Milner (1987, p. 14) quando afirma que:

[...] não há designação unívoca para o lugar dos equívocos. Somente um semblante pode se prestar a isso, ela mesmo trabalhando pelo equívoco cujo real é aqui objetivado: compreende-se que seja apropriado o nome que Lacan forjou: lalangue ${ }^{4}$. [...] É lalangue, em toda língua, o registro que consagra ao equívoco. Equívocos que desestratificam, confundem sistematicamente som e

4 Termo introduzido por Lacan e muito traduzido por alíngua. Segundo Porge (2014, p. 79), "designa uma integral de equívocos de que é composta a língua dita materna para um sujeito, que determina o funcionamento inconsciente, tanto em seus tropeços quanto em seu mergulho no gozo do corpo". 
- | Jogos linguageiros na infância e o enlace poético

sentido, menção e uso, escrita e representado, impedindo, com isto, que um estrato possa servir de apoio para destrinchar um outro.

Ainda segundo Milner (1987, p. 13), “o real equívoco resiste: a língua não cessa de ser por ele desestratificada". Esse equívoco, que se caracteriza pela falta de correspondência, tem importância estrutural, por deixar seu resto, seu vazio de sentido, visto que, em relação à fala da criança, atravessando-a, está a faixa do nonsense, da brincadeira e também das possibilidades poéticas. Talvez seja por isso que, ao tratar do conceito de lalangue no Seminário XX, Lacan (1985, p. 190) diz:

A linguagem, sem dúvida, é feita de lalangue, é uma elucubração de ser sobre lalangue. Mas o inconsciente é um saber, um saber-fazer com lalangue. E o que sabe fazer com lalangue ultrapassa de muito o de que podemos dar conta a título de linguagem.

É nesse ato de esvaziamento, da permuta de formas e sentidos, em que o sentido consensual fracassa e por fracassar permite a possibilidade dos jogos linguageiros, como as associações realizadas pelas crianças nos exemplos mostrados anteriormente, que enxergamos nos textos da tradição oral e literários possibilidades poéticas.

Sob esse aspecto Belintane (2013, p. 35) afirma que "no termo lalangue encontramos a lalação infantil", que seria, segundo o autor, "aquela reduplicação de sílabas, ou, ainda, os prolongamentos sonoros de vogais e até mesmo a intervenção de um ou outro ruído próximo das consoantes que o bebê produz, sobretudo quando está sozinho no berço".

Para Belintane (2013, p. 36), "o lala do termo francês nos indica que estamos nos referindo a uma dimensão das possibilidades da linguagem em que o sentido consensual fracassa e por fracassar vai permitir a possibilidade dos jogos linguageiros", comuns na infância. Dessa forma, como disse Lacan (1985, p. 190):

Lalangue nos afeta primeiro por tudo que ela comporta como efeitos que são afetos. Se se pode dizer que o inconsciente é estruturado como uma linguagem, é no que os efeitos de lalangue, que já estão lá como saber, vão bem além de tudo que o ser que fala é suscetível de enunciar.

Nesses laços de lalangue, no equívoco, no nonsense e nos jogos perfila um sujeito do desejo inconsciente, como na fala de Rafaela citada anteriormente, que segundo Belintane (2013, p. 36): 
O signo "que-se-chama", pura holófrase, efeito de lalangue, torna-se um significante, que remete à "solidão", desvelando uma verdade que entremostra uma subjetividade desejante que nomeia seu urso de brinquedo acumulando o prazer da cantiga ouvida dias antes.

O importante a compreender, segundo esse autor, é:

Que um elemento metonímico toma as rédeas do processo (que pode fazê-lo também pela via da metáfora), ou seja, um elemento ou outro condensará os sentidos para que ocorra a remissão a um outro, tendo claro que a condensação implica o esvaziamento do signo para que ele ceda sua materialidade a outros sentidos. (BELINTANE, 2013, p. 37).

Assim, procuramos indicar que a entrada do infans na língua se dá a partir da emergência de uma subjetividade de entre-textos com todas as possibilidades de interferências dos textos da tradição oral e literários e de modos de o sujeito se posicionar.

\section{Aquisição, poesia, psicanálise e jogos linguageiros}

Campos (2000), ao aproximar a poesia da linguagem da criança, se interroga acerca dos fatos linguísticos da aquisição da linguagem poderem ser interpretados como os fatos literários. E numa tentativa de responder a tal indagação, a autora traz a literariedade como ponto chave para tal aproximação, visto que para esta autora é a literariedade que liga à ideia de um emprego peculiar da linguagem, ao efeito de estranhamento provocado pelo texto, através dos mecanismos e recursos disponíveis na linguagem. Esta mesma literariedade, segundo Jakobson (2007), é o que torna uma determinada obra literária.

Para Campos (2000, p. 1)

[...] embora a fala da criança seja esteticamente apartada da palavra do poeta, de quem (ao contrário da criança) se pode falar em um (re)conhecimento da diferença, da ruptura entre o fazer poético e a linguagem do cotidiano, pode-se dizer que a linguagem infantil tem em comum com a literariedade o efeito de estranhamento provocado pelos movimentos da língua que 'dão lugar a enunciados insólitos, arranjos desconcertantes entre os significantes incorporados'. 
- | Jogos linguageiros na infância e o enlace poético

Dessa forma, ao refletirmos acerca da interpretação da mãe em direção à fala da criança, recorremos à hipótese de Castro (1997, p. 128) de que, em tal movimento interpretativo, "faz-se em uma tensão entre uma identificação ou reconhecimento de uma língua e um estranhamento provocado pelos deslocamentos causados pelos movimentos da língua presentes na fala da criança". Tal efeito também ocorre na poesia, em que o leitor sofre o estranhamento da ruptura, em que toda significação se estanca e de onde se avança pela ficção.

É o que pode ser visto no Livro sobre Nada (1980), do poeta Manoel de Barros, nos versos "um abridor de amanhecer", "um alarme para o silêncio", em que o autor fala sobre o nada, coisa nenhuma. Lançando mão de uma poética que desaprende e regride a palavra ao seu princípio, desembocando no que Castelo Branco (1994) chamou de "umbigo da escrita".

Sobre este aspecto, Sobral e Viana (2014, p. 439) afirmam que "na poesia, a linguagem não se submete à significação estática, a palavra se desdobra produzindo efeitos poéticos, uma licença se abre para que algo se produza visando um efeito estético e uma abertura à pluralidade de sentidos".

As autoras afirmam ainda que:

A palavra da criança, como a do poeta, cria outra realidade no lugar daquela já existente, uma realidade imaginada com elementos os quais a realidade concreta não comporta. Nesse sentido a criança cria um jeito de usar a linguagem, em suas brincadeiras a favor de seus desejos. (SOBRAL; VIANA, 2014, p. 442).

Dessa forma, as crianças, assim como os poetas, brincam com as palavras, parecendo saber que, não havendo palavras suficientes para nomear, ampliam o sentido destas, produzindo metáforas. Essas são nomeadas por Lacan (1998) de mecanismo próprio da poesia e função primordial do significante, essencial às formações do inconsciente e à criação de novos sentidos.

Ao inventar e subverter certas palavras, a criança faz um deslocamento de sentido de uma palavra a outra se assemelhando à questão dos efeitos poéticos, demonstrando um jeito inventivo de usar a linguagem. No exemplo dado por Lacan (1975) sobre $A$ função criativa da palavra, se afirma ser: 
A palavra instituída como tal na estrutura do mundo semântico que é o da linguagem. A palavra não tem nunca um único sentido, o termo, um único emprego. Toda palavra tem sempre um mais-além, sustenta muitas funções, envolve muitos sentidos. Atrás do que diz um discurso, há o que ele quer dizer, e, atrás do que quer dizer, há ainda um outro querer dizer, e nada será nunca esgotado - se não é que se chega ao fato de que a palavra tem função criadora e faz surgir a coisa mesma, que não é nada senão o conceito. (LACAN, 1975, p. 275).

Para ilustrar esse mais-além citado por Lacan, trazemos um exemplo dado por Sobral e Viana (2014, p. 442, grifo das autoras), no qual as autoras relatam uma situação chamando atenção para:

O gozo de Antônio, um garoto de 5 anos, ao relatar, no consultório, o desconforto de sua professora em uma situação na qual ela atribuiu a turma o conceito máximo de comportamento estabelecido pela escola, nomeado de Elegante, como forma de elogiar os alunos. A professora então diz: “Hoje a turma está Ele..."; e Antônio puxa o coro: "Elefante". A professora então repete: "Hoje a turma está Ele..."; e a turma responde como Antônio: "Elefante". Antônio chega irritado, dizendo ter recebido um bilhete da professora e faz a seguinte construção: "É que os adultos gostam de adultar as palavras".

Na fala de Antônio, vemos o que Lacan (1975) chama de traço de identidade, quando afirma ser, em certa medida, metafórico o emprego de toda palavra, visto que a elaboração e o uso dela é particular a cada falante. É nessa singularidade que, segundo Lacan (1975, p. 273), “a palavra é essencialmente o meio de ser reconhecido, ela está aí antes de qualquer coisa que haja atrás". Tal efeito de estranhamento é passado de forma divinal pelos poetas, como nos versos de Manoel de Barros (1996, p. 53):

Quem acumula muita informação,

pede o condão de

adivinhar: divinare.

Os sabiás divinam.

É de "estames do som 5 ", como sinaliza a epígrafe do presente estudo, a divinos encantos dos sabiás que nos surpreendem a estranheza com tudo o que é mais íntimo e

5 Fio de undir e tecer. 
- | Jogos linguageiros na infância e o enlace poético

familiar, irrompendo o que deveria permanecer oculto, mas veio à luz. Abrindo fendas, revelando e ocultando ao mesmo tempo o desamparo e a incompletude do ser.

É neste "abrir um descortínio para o arcano" que Morais (2006, p. 46) cria algumas aproximações entre a poesia e a psicanálise afirmando que:

Tanto a psicanálise quanto a poesia procuram vestígios, buscam dar contornos ao indizível, ao objeto perdido desde sempre. Num distanciamento com linguagem... De uma ignorância, no sentido de uma desaprendizagem, de uma quebra com o ver cotidiano, olhar como a primeira vez, com o deslumbramento de um dessaber, compromisso com nada.

Comparando o poeta ao artesão de palavras, como João Cabral de Melo Neto, ou ao Criador, mas sem a onipotência divina, criando do conflito e não da paz celestial. Como o fez Mário Quintana (2006),

\section{E eis que, tendo Deus descansado \\ no sétimo dia, os poetas continuaram \\ a obra da Criação.}

Dessa forma, ao discutirmos uma possível aproximação entre Aquisição de linguagem, Literatura - poesia - e Psicanálise, percebemos a existência de um poder de criação capaz de instaurar novas realidades.

\section{Considerações finais}

Lacan, em A função criativa da palavra (1975, p. 272), situa a linguagem numa dimensão fundadora do humano, afirmando que "se a emoção pode ser deslocada, invertida, inibida, se está engajada numa dialética, é que está presa na ordem simbólica, donde as outras ordens, imaginária e real, tomam lugar e se ordenam". E, esta dialética exigida pela dimensão da palavra, de um reconhecimento, que, segundo Lacan (1975), não se trata das regras da linguagem para o entendimento do outro, mas do reconhecimento de um traço que torne o sujeito singular, destacando-o dos demais, conferindo-lhe um lugar.

Lugar este marcado por uma fala vinda dos pais ou dos cuidadores. Fala que inscreve a criança na linguagem familiar, bem como nas primeiras marcas de sua história. E entre palavra e brincadeiras, os pais convidam a criança para o jogo, apontando haver um mais além do objeto e que esse mais além está nos limites da linguagem. Dessa forma, 
a criança fala brincando, seja interpretando sua realidade, seja criando outras mais, de acordo com seu desejo, que aparece nas chamadas manifestações do inconsciente, forçando passagem e, em uma brecha de linguagem, faz aparecer sua marca.

Para Sobral e Viana (2014), a fala da criança tenta representar o objeto perdido e o desejo da volta deste, apresentando um sujeito que enuncia um desejo, joga com as palavras e obtém prazer com isso. Mostrando que, se nossa infância nos fascina, é talvez por estarmos enlaçados pelo encantamento materno, lugar das primeiras impressões, fonte de "quando a criança garatuja o verbo para falar o que/não tem" (MORAIS, 2006, p. 53) e do material poético de muitos autores.

A fala da criança, assim como a poesia, nos ensina que as palavras podem ter combinações infinitas, a partir do "instante em que o desejo do ser falante corta as cadeias significantes" (MORAIS; SOBRAL, 2014, p. 448).

\section{Referências}

BANDEIRA, M. Itinerário de Pasárgada. In: BANDEIRA, M. Poesia completa e prosa. Rio de Janeiro: Nova Aguiar, 1996.

BARROS, M. de. Livro sobre o nada. 2. ed. Rio de Janeiro: Record, 1996.

BELINTANE, Cr. Oralidade e alfabetização: uma nova abordagem da alfabetização e do letramento. São Paulo: Cortez, 2013.

CAMPOS, C. M. Processos metafóricos e metonímicos - Da poesia à linguagem da criança. In: Encontro do círculo de estudos linguísticos do sul, 4, 2000, Curitiba, PR. Anais... Curitiba, Mídia Curitibana, 2001. Disponível em http://www.celsul.org.br/Encontros/04/ artigos/028.htm. Acesso em: 20 out. 2010.

CASCUDO, L. da C. Contos tradicionais do Brasil. Rio de Janeiro: Ediouro, 1998.

CASTELO BRANCO, L. A traição de Penélope. São Paulo: Annablume,1994.

CASTRO, M. F. P. de. A interpretação: a fala do outro e a heterogeneidade da fala da criança. Letras. Revista do Mestrado em Letras, Santa Maria: UFSM, p. 125-138, jan./jun. 1997. 
- | Jogos linguageiros na infância e o enlace poético

FREUD, S. Escritores criativos e devaneios. In: Edição standart brasileira das obras psicológicas completas de Sigmund Freud. v. IX. Rio de Janeiro: Imago, 1908 [1907].

JAKOBSON, R. Linguística, poética, cinema. São Paulo: Perspectiva, 2007.

JAKOBSON, R. Dois aspectos da linguagem e dois tipos de afasia. Linguística e Comunicação. São Paulo: Cultrix, 1995.

LACAN, J. Outros escritos. Rio de Janeiro: Jorge Zahar, 2003.

LACAN, J. Escritos. Rio de Janeiro: Jorge Zahar, 1998.

LACAN, J. Seminário, livro 20: mais ainda. (1981/1901). Tradução M. D. Magno. Rio de Janeiro: Zahar, 1985.

LACAN, J. O seminário. Livro 1. Os Escritos técnicos de Freud. Texto estabelecido por Jacques Alain Miller. Versão brasileira de B. M. Magno. Rio de Janeiro: Jorge Zahar, 1975.

LEMOS, C. T. G. de. Uma crítica radical à noção de desenvolvimento na Aquisição da Linguagem. In: LIER-DE VITTO, M. F. (org.). Aquisição, Patologias e Clínica de Linguagem. v. 1. São Paulo: EDUC FAPESP, 2006.

LEMOS, C. T. G. de. As vicissitudes da fala da criança e de sua investigação. Cadernos de Estudos Linguísticos, Campinas: UNICAMP, v. 42, p. 41-69, 2002.

LIMA, J. de. Antologia poética. Rio de Janeiro: José Olympio, 1978.

MORAIS, M. B. L. Poesia, psicanálise e ato criativo: uma travessia poética. Estudos de psicanálise, Rio de Janeiro, n. 29, p. 45-56, set. 2006.

MILNER, J. C. O amor da língua. Porto Alegre: Artes Médicas, 1987.

PORGE, E. Voz do eco. Tradução Viviane Veras. Campinas: Mercado de Letras, 2014.

QUINTANA, M. Caderno. Rio de Janeiro: Editora Globo, 2006.

RAMOS, G. São Bernardo. Rio de Janeiro: Record, 1996. 
RAMOS, G. Infância. São Paulo: Martins, 1992.

SOBRAL, P. O.; VIANA, T. de C. A fala criativa das crianças e os efeitos poéticos: recortes a partir da clínica psicanalítica com crianças. Estilos clínicos, São Paulo, v. 19, n. 3, p. 436450, set/dez. 2014.

COMO CITAR ESTE ARTIGO: SILVA, Elisangela Maria da; CARVALHO, Glória Maria Monteiro de. Jogos linguageiros na infância e o enlace poético. Revista do GEL, v. 16, n. 3, p. 127-139, 2019. Disponível em: https://revistadogel.gel.org.br/

DOI: http://dx.doi.org/10.21165/gel.v16i3.2611

Submetido em: 12/10/2019 | Aceito em: 02/12/2019. 